\title{
Projeto de ensino de programação para alunos de ensino médio: Uma análise do cenário e das percepções das oportunidades
}

\author{
1Andréa Sabedra Bordin, ${ }^{1}$ Wolgan Ens Quepfert \\ ${ }^{1}$ Universidade Federal do Pampa (UNIPAMPA) - 97.546-550 - Alegrete - RS - Brasil \\ andreabordin@unipampa.edu.br.br, ens.wolgan@gmail.com
}

\begin{abstract}
Programming teaching projects for students of basic education allow the development of logical-computational thinking and instrumentalization to solve various problems. This article reports the methodology of a programming teaching project for high school students in public schools and analyzes the scenario and the students' perceptions about the opportunities of access to projects in this area. App Inventor workshops were offered to students from seven state schools and perceptions were collected at the end of each workshop and at the end of the project. The results show that opportunities for access to such projects are scarce and that students feel more confident in their ability to create technology rather than just consuming them.
\end{abstract}

Resumo. Projetos de ensino de programação permitem o desenvolvimento do pensamento lógico-computacional e a instrumentalização para a resolução de problemas diversos. Este artigo relata a metodologia de um projeto de ensino de programação para alunos de ensino médio de escolas públicas e analisa o cenário $e$ as percepções dos alunos acerca das oportunidades de acesso à projetos nessa área. Foram oferecidas oficinas com a ferramenta App Inventor para alunos de sete escolas estaduais e as percepções foram coletadas ao final de cada oficina e ao final do projeto. Os resultados mostram que as oportunidades de acesso a projetos dessa natureza são escassas e que os alunos se sentem mais confiantes em sua capacidade de criar tecnologia ao invés de apenas consumi-la.

\section{Introdução}

Instituições de ensino, educadores e pesquisadores, vêm percebendo a importância da introdução do ensino de computação desde a educação básica. Essa percepção deriva da necessidade da formação de indivíduos que saibam lidar e se adequar à constante mudança nos diversos tipos de tecnologias existentes na atualidade.

Nesse contexto o ensino de programação se destaca por permitir o desenvolvimento do pensamento lógico-computacional e a instrumentalização para a resolução de problemas diversos. Dessa forma, vários projetos que promovem o ensino de programação para alunos de educação básica vêm sendo propostos nos últimos anos, sendo alguns mais focados no ensino fundamental como o proposto por Adriano et al. (2015) e Anelise Lemke et al. (2016) e outros tendo como público-alvo alunos do ensino médio como os de Natália Nascimento et al. (2017) e Finizola et al. (2014).

No processo de aprendizagem de programação alguns fatores apontados como dificultadores são a sintaxe complexa das linguagens de programação tradicionais e o excesso de funcionalidades das ferramentas de construção de código, como destaca Scaico et al. 
VII Congresso Brasileiro de Informática na Educação (CBIE 2018)

Anais do XXIV Workshop de Informática na Escola (WIE 2018)

(2012). Como alternativa, projetos que insiram a programação de forma lúdica, utilizando dispositivos móveis, os quais segundo Bévort e Belloni (2009) a maior parte da população possui o conhecimento mínimo para o manuseio, auxiliam a minimizar esse problema.

Abordar a programação para dispositivos móveis com ferramentas que possibilitam a construção rápida de aplicativos utilizando a lógica de blocos, permite que o aluno visualize rapidamente o resultado de construção em seu próprio aparelho, despertando sua curiosidade e estimulando o pensamento computacional, aumentando suas perspectivas de resolução de problemas de forma mais lógica. A ferramenta App Inventor é uma alternativa com este fim, pois permite a construção de aplicativos para o sistema operacional Android através da conexão de blocos lógicos como se fossem quebra-cabeças, caracterizando-se como uma opção mais amigável para iniciantes e que já foi utilizada em outras ações, como as propostas por Ribeiro, Manso e Borges (2016), Natália Nascimento et al. (2017) e Finizola et al. (2014).

O projeto de ensino de programação PampaCode é uma atividade de extensão universitária desenvolvida por acadêmicos e docente dos cursos de Ciência da Computação e Engenharia de Software da Universidade Federal do Pampa (UNIPAMPA), cujo objetivo é levar o ensino de programação para dispositivos móveis através da ferramenta App Inventor para alunos de ensino médio de escolas públicas do município de Alegrete.

O projeto foi executado de forma pioneira, ao longo do ano de 2017, através de uma metodologia que permitiu que a cobertura de sete das oito escolas públicas do município. $\mathrm{O}$ contato com a realidade das escolas e a avaliação dos alunos a cada oficina concluída gerou elementos para uma investigação mais aprofundada, no ano de 2018, acerca das oportunidades envolvendo informática na escola e quais os impactos ou influências que a participação no projeto ocasionou.

Este artigo relata a experiência deste projeto de ensino de programação e analisa o cenário de oportunidades e as percepções a posteriori dos alunos em relação a ser um produtor e não apenas um consumidor de tecnologias, o grau de interesse pela área de informática, qual a influência da participação no projeto na escolha do curso superior e na percepção de que existe uma opção gratuita de acesso ao ensino superior no município e por fim quais as principais demandas dos alunos em termos de aprendizagem de tecnologias.

\section{Metodologia}

Nesta seção são descritas as etapas metodológicas do projeto de ensino de programação e da avaliação do cenário de oportunidades e das percepções dos alunos meses após a conclusão das oficinas. O projeto foi conduzido ao longo de todo o ano de 2017 através de uma metodologia composta por quatro etapas: oferta de uma oficina piloto, planejamento das oficinas, execução e avaliação.

A oferta da oficina piloto foi executada no final do ano de 2016 de forma colaborativa com o Instituto Federal Farroupilha (IFFar), parceiro na fase inicial do projeto, com o objetivo de validar o formato em relação ao tempo, conteúdo e número necessário de tutores para atender cada oficina como relatado em Bordin et al. (2017).

$\mathrm{Na}$ etapa de planejamento foram definidas quais seriam as escolas públicas a serem atendidas, o cronograma de execução, bem como foram refinadas algumas decisões em relação a experiência positiva da oficina piloto. Foi definido que a oficina seria desenvolvida através da construção de um Quiz (jogo de perguntas e respostas), que a duração total de cada oficina seria de seis horas divididas em dois encontros de três horas e que cada oficina deveria ser ministrada por no mínimo 3 acadêmicos. 
A etapa de execução consistiu em duas atividades, sendo elas a divulgação e a execução propriamente dita de cada oficina. $\mathrm{Na}$ etapa de divulgação, a equipe executora se dirigia até a escola para apresentar o projeto, onde abordava conceitos introdutórios sobre programação, sua presença no dia-a-dia das pessoas e o potencial para a solução de problemas diversos. Ao final da apresentação, era distribuído um formulário de inscrição e logo após era feita a seleção dos alunos baseada no justificativa do porquê o aluno desejava participar da oficina.

As oficinas foram ofertadas para seis escolas, no laboratório de informática da universidade. Para algumas escolas houve a possibilidade de disponibilizar transporte, considerando a distância entre a escola e a universidade. Cada oficina foi dividida em dois encontros em dias alternados de uma mesma semana.

No primeiro encontro de cada oficina, era realizada uma introdução à ferramenta App Inventor com ênfase na elaboração de interfaces gráficas, abordando tópicos como: formulários, botões, plano de fundo e tipografia. Ao final do encontro, os alunos recebiam uma folha de prototipação onde deveriam planejar e desenhar sua proposta de quiz, a ser desenvolvido no segundo encontro.

O segundo encontro era destinado a construção da parte lógica dos quizzes, para isso, foram introduzidos componentes mais avançados da ferramenta como a inserção e troca de telas, mensagens de alerta, sensor de movimento (acelerômetro), e como esses componentes interagem com a interface gráfica através dos blocos lógicos. Os alunos tiveram a liberdade para definir a temática das perguntas, onde podemos destacar exemplos como Geometria, LGBT e Animes.

Ao final de cada oficina os alunos realizaram uma avaliação sobre a equipe executora, as atividades realizadas, o que mais gostaram, o que menos gostaram e tiveram um espaço para dar sugestões. A Figura 1-a, ilustra o protótipo do aplicativo, enquanto a Figuras 1-b e a Figura 1-c mostram os alunos com os resultados das atividades em seus dispositivos.
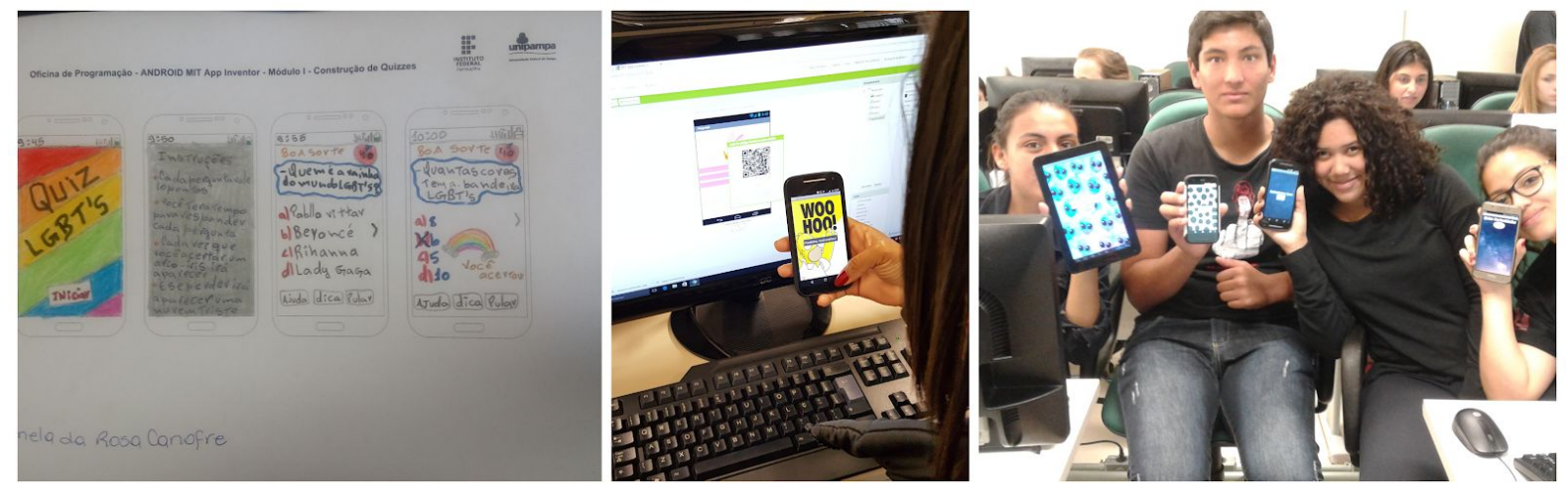

Figura 1 - a ) Protótipo do quiz b, c) Visualização do aplicativo no smartphone

\subsection{Avaliação do cenário e percepções sobre as oportunidades}

Essa avaliação teve o objetivo de coletar dados a respeito das oportunidades de acesso a cursos extra classe na área de Informática e as percepções dos alunos concluintes das seis oficinas no ano seguinte (2018) ao oferecimento das mesmas, mais especificamente seis meses após a conclusão da última oficina. Foi elaborado um instrumento de pesquisa na forma de questionário no qual buscou-se identificar:

a) o perfil dos alunos: se está cursando ou já concluiu o ensino médio; no caso de ter concluído, se está estudando e/ou trabalhando ou nenhuma das opções; se está fazendo um 
VII Congresso Brasileiro de Informática na Educação (CBIE 2018)

Anais do XXIV Workshop de Informática na Escola (WIE 2018)

curso superior, qual o nome do curso; se não está fazendo um curso superior, qual curso gostaria de fazer.

b) o número e a temática dos projetos de informática que os alunos participaram durante o ensino médio.

c) as percepções e possíveis influências decorrentes da participação no projeto de ensino de programação no que tange a capacidade de aprender e produzir tecnologias ao invés de apenas utilizá-las, se participar da oficina permitiu que tivesse ideias e produzisse aplicativos e em caso positivo quais foram as ideias e apps; se a participação na oficina despertou o interesse pela área de Informática, despertou o interesse em cursar um curso superior na área de Informática, se participar do projeto no ambiente da universidade permitiu perceber que existe uma opção de acesso gratuito ao ensino superior na cidade e, por fim, quais as tecnologias relacionadas a informática que gostariam de aprender.

O questionário foi enviado através de email e alguns de forma presencial para os 68 alunos que concluíram as seis oficinas oferecidas em 2017. Nessa pesquisa foram excluídos os concluintes da oficina piloto oferecida em 2016.

\section{Resultados e Discussão}

Essa seção apresenta primeiramente os resultados compilados das avaliações feitas no último encontro de cada uma das seis oficinas. Na Tabela 1 são exibidos dados referentes ao número de alunos selecionados para cada oficina, número de participantes no primeiro dia, percentual de desistência em relação ao número de selecionados, número de concluintes e percentual de desistência em relação ao número de participantes no primeiro dia da oficina.

Tabela 1: Número de alunos selecionados, participantes e concluintes nas oficinas.

\begin{tabular}{|c|c|c|c|c|c|}
\hline Oficina/Escola & \#Selecionados & \#Participantes & \%Desistência 1 & \#Concluintes & \% Desistência 2 \\
\hline CIEP & 25 & 12 & $52 \%$ & 9 & $25 \%$ \\
\hline IEEOA & 24 & 18 & $25 \%$ & 14 & $23 \%$ \\
\hline DR & 22 & 7 & $68 \%$ & 4 & $43 \%$ \\
\hline EZ & 33 & 24 & $22 \%$ & 20 & $40 \%$ \\
\hline JB & 23 & 10 & $58 \%$ & 6 & $0 \%$ \\
\hline TAN & 27 & 15 & $44 \%$ & 15 & \\
\hline Total & 100 & 86 & & 68 & \\
\hline
\end{tabular}

Destacam-se os percentuais altos de desistência de participação no primeiro encontro, embora não se saiba apontar os principais motivos, visto que o transporte para quatro das seis escolas mais distantes foi oferecido e a divulgação e seleção da oficina tenha sido realizada sempre na semana anterior à oferta da mesma. Os percentuais de desistência do segundo/último encontro são menores e portanto mais positivos, mas careceriam de uma investigação mais detalhada. 
VII Congresso Brasileiro de Informática na Educação (CBIE 2018)

Anais do XXIV Workshop de Informática na Escola (WIE 2018)

Para explorar as respostas das questões abertas do questionário, foi aplicada a técnica de análise de conteúdo (CÂMARA, 2013). Dessa forma foi possível agrupar fragmentos de interesse de temáticas semelhantes. As Tabelas 2 e 3 exibem os temas e exemplos de respostas que justificam sua categorização.

Tabela 2: Classificação das respostas da questão "O que você mais gostou?"

\begin{tabular}{|l|l|l|}
\hline Temas & Exemplos de Respostas & Freq. \\
\hline Atividades Práticas & "Foi a parte de montar os blocos e colocar as imagens.” & 26 \\
\hline Aprendizado & “Aprender a criar algo que é muito útil na nossa vida.” & 18 \\
\hline Todo o Projeto & “Tudo de certa forma é legal.“ & 10 \\
\hline Equipe Executora & “A equipe é maravilhosa alegre e competente.” & 9 \\
\hline Oportunidade & “Criar aplicativo, nunca pensei que teria a oportunidade...” & 7 \\
\hline Capacidade & "Saber que eu tenho capacidade de aprender e desenvolver um jogo.” & 5 \\
\hline Infraestrutura & “...conhecer a unipampa e...” & 2 \\
\hline
\end{tabular}

Tabela 3: Classificação das respostas da questão "O que você menos gostou?"

\begin{tabular}{|l|l|l|}
\hline Temas & Exemplos de Respostas & Freq. \\
\hline Lanche & "A falta de café.” & 18 \\
\hline Duração & “Apenas dois dias, seria legal se houvesse mais.” & 11 \\
\hline Dificuldade no aprendizado & "A dificuldade em arrumar alguns blocos no 20 dia” & 6 \\
\hline Infraestrutura & “A rede não colaborou” & 5 \\
\hline Divulgação & "Acho que a pouca quantidade de pessoas no curso...” & 2 \\
\hline Atividades & "Elaborar perguntas” & 1 \\
\hline
\end{tabular}

A análise mostra resultados bastante satisfatórios, com temas relacionados ao aprendizado geral e ao aprendizado focado nas atividades práticas com as maiores frequências, o que demonstra que os alunos têm noção da importância e do valor que projetos como esse tem na sua formação complementar e que gostaram da forma como a ferramenta App Inventor permite a construção de aplicativos.

Os temas relacionados à capacidade e oportunidade agruparam respostas que indicam uma falta de confiança ou estima que pode estar relacionada ao fato de que alunos de escolas públicas não costumam ter oportunidades de acesso ao conhecimento oferecido nesse tipo de oficina. Isso pode ser verificado através das demonstrações de surpresa dos participantes ao descobrirem que atividades de criação de uma app simples são muito mais palpáveis do que eles imaginavam. 
Entende-se que projetos dessa natureza produzam um sentimento de empoderamento e apropriação de tecnologias que pode se refletir em outros processos de aprendizagem durante a vivência escolar dos estudantes. Cabe destacar que foram as respostas agrupadas nos temas capacidade e oportunidade que motivaram a investigação posterior acerca da realidade escolar dos alunos em termos de projetos que envolvam informática e dos impactos que a participação nesse projeto gerou.

O não oferecimento de um lanche foi o item que os alunos menos gostaram e está diretamente relacionado com o perfil sócio-econômico dos alunos da maioria das escolas, podendo este ser um fator que relacionado com os índices de desistência. Todos os demais itens são subsídios que servirão para orientar as futuras atividades do projeto PampaCode.

\subsection{Resultados da avaliação do cenário e das percepções sobre as oportunidades}

O questionário foi respondido por 44 dos 68 alunos concluintes. Alguns alunos não conseguiram ser acessados porque mudaram-se de cidade ou tiveram seus contatos (email, telefone) trocados.

O perfil dos respondentes pode ser verificado na Figura 2 a e Figura $2 b$, onde 79,5\% (35) ainda está cursando o ensino médio e 20,5\% (9) já o concluíram. Do percentual de concluintes, a maioria (5 alunos) está estudando, sendo que 4 estão no ensino superior e 1 está no ensino técnico. Desses 4, 2 escolherem estudar Engenharia de Software, 1 Engenharia Mecânica e 1 Engenharia Elétrica.

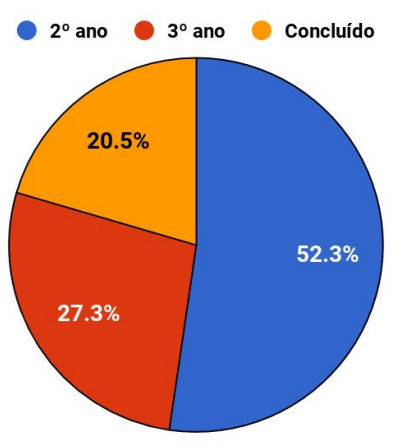

Figura 2a - Situação de escolaridade

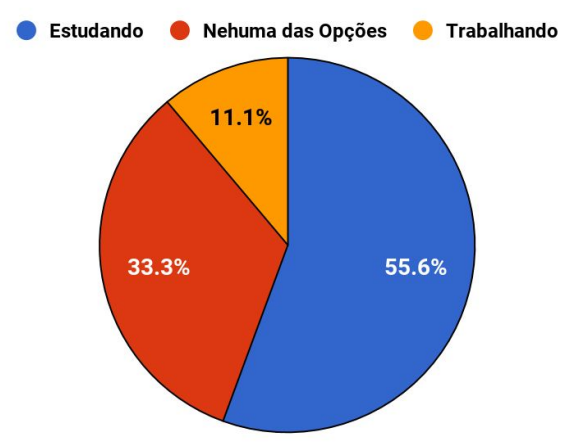

Figura 2b - Situação dos concluintes do ensino médio

Ainda em relação ao perfil dos respondentes, foi questionado para aqueles que não estavam no ensino superior, qual o curso que gostariam de fazer, o que pode ser visualizado na Figura 3. Dos 35 alunos, obteve-se respostas de 24 alunos, sendo que alguns informaram mais de um curso. 
VII Congresso Brasileiro de Informática na Educação (CBIE 2018)

Anais do XXIV Workshop de Informática na Escola (WIE 2018)

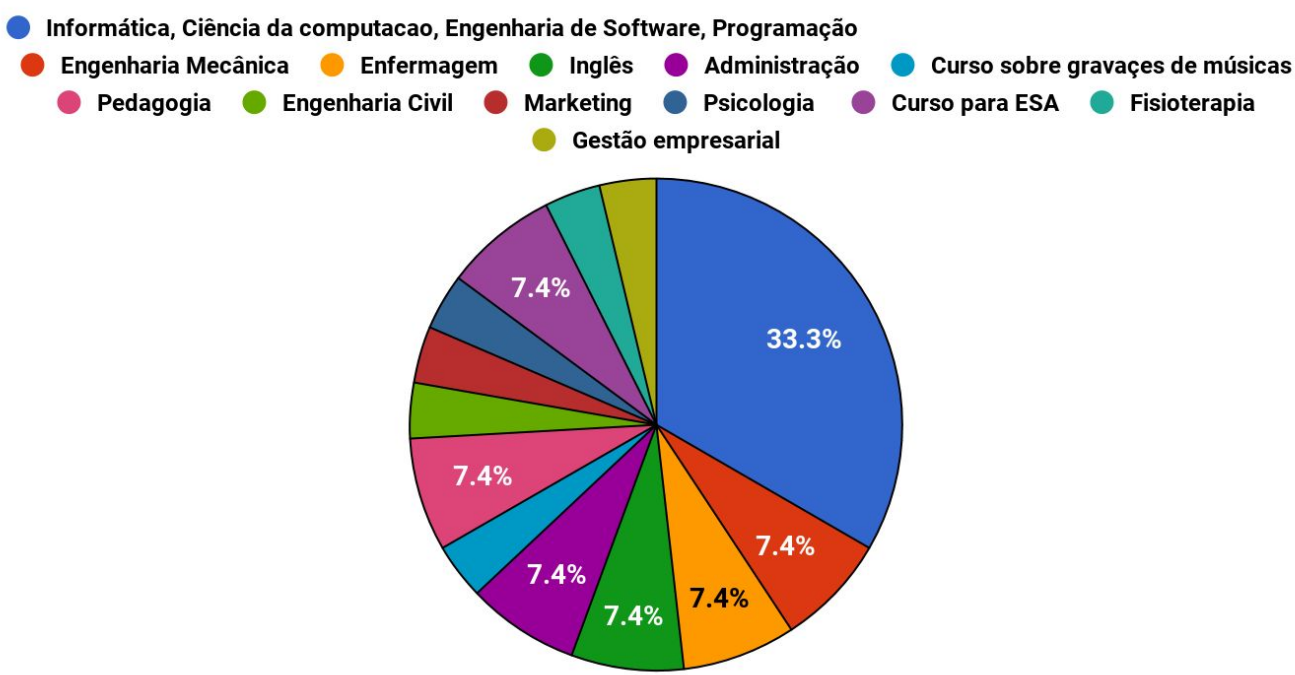

Figura 3 - Cursos que os alunos do ensino médio gostariam de fazer.

Em relação à questão "Quantos e quais cursos de computação/informática você fez durante o ensino médio?", 23 alunos relataram que somente realizaram a oficina de App Inventor e 7 alunos informaram que realizaram "apenas 1", não informando o nome do curso, o que leva a crer que se trata da própria oficina do projeto. Dois (2) alunos informaram que a escola oferece aulas de informática, três (3) alunos não lembram ou não sabem informar, dois (2) alunos informaram que realizaram curso de informática, três (3) afirmam ter feito dois cursos, sem informar quais seriam e quatro (4) alunos especificaram quantidades maiores que 2 cursos, também sem especificar os cursos.

As respostas dessa questão retratam um cenário escasso em termos de oportunidade de acesso a cursos que envolvam informática em geral e, de forma mais específica, aqueles que contemplem conhecimentos de programação, indicando que existe um amplo espaço para que sejam ofertados. No entanto, a experiência no projeto PampaCode, único no propósito de ensinar programação para alunos de escolas públicas de ensino médio, mostrou números medianos de participantes no primeiro encontro e concluintes das oficinas.

O conjunto de respostas que segue, investiga a percepção e os possíveis impactos ou influências que a participação nesse projeto de ensino de programação causou nos estudantes. Primeiramente verificou-se em qual medida a participação no projeto fez com que o aluno percebesse que é capaz de produzir tecnologia e não apenas consumi-la. As respostas apontaram que quase a totalidade (42) dos respondentes concordam com essa afirmação e apenas 2 alunos se mostraram indiferentes.

$\mathrm{Na}$ sequência indagou-se se os alunos tiveram alguma ideia e produziram algum app depois que concluíram o curso. A Figura 4 mostra que quase 50\% dos alunos tiveram ao menos ideias, sendo que $13,6 \%$ informaram que produziram algum app. Dentre os apps citados estão: projeto de perguntas, jogo para a feira de profissões da escola, quizz de perguntas sobre história do Brasil, app sobre kanban, fórum de respostas a perguntas variadas, quiz de Química. 
VII Congresso Brasileiro de Informática na Educação (CBIE 2018)

Anais do XXIV Workshop de Informática na Escola (WIE 2018)

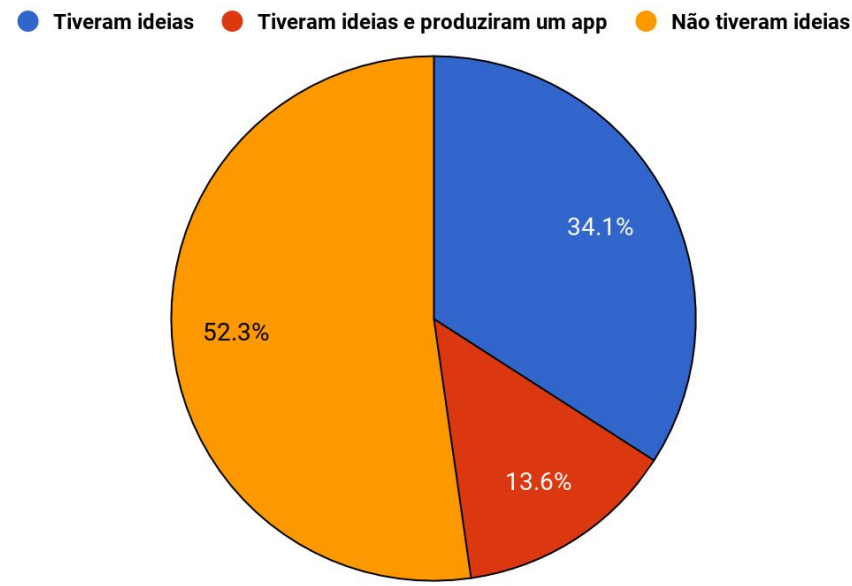

Figura 4 - Respostas da questão 'Você teve alguma ideia e/ou produziu alguma app depois que concluiu o curso?'

A Figura 5 mostra as respostas das questões sobre o interesse dos alunos na área da informática, onde verifica-se que para a grande maioria dos alunos (21), a participação na oficina despertou o interesse em conhecer mais a área de Informática. Já na Figura 6, as respostas mostram que participar da oficina não fez a maioria dos alunos optar ou ter vontade de fazer um curso superior na área de Informática.

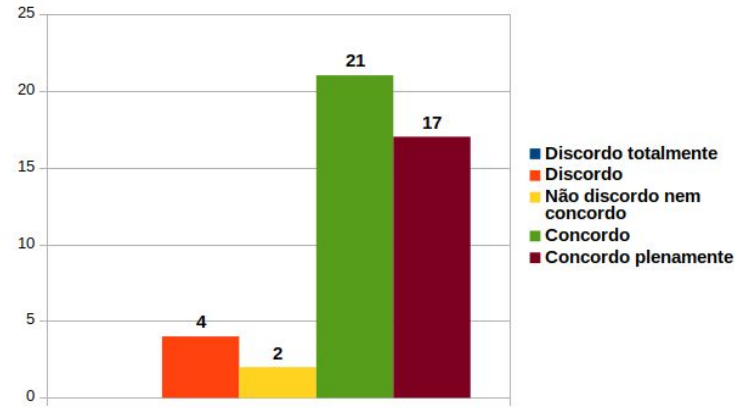

Figura 5 - Respostas da questão 'Participar deste projeto despertou meu interesse em conhecer mais a área de Informática'.

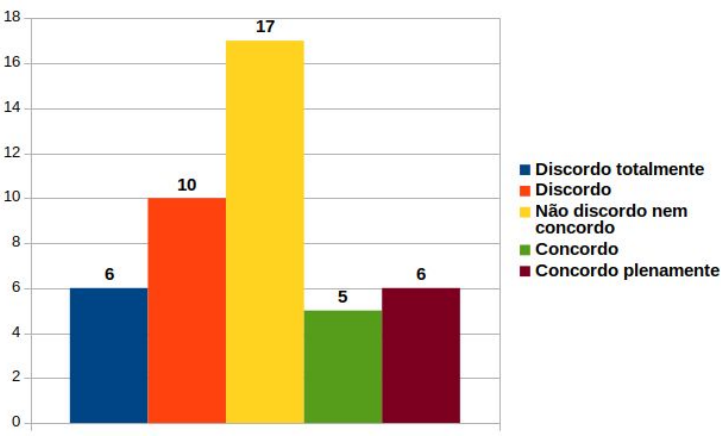

Figura 6 - Respostas da questão 'Participar deste projeto me fez optar por um curso superior em Informática'.

Foi investigado também em que medida participar do projeto nas dependências da universidade e, consequentemente interagir com o ambiente universitário, fez os alunos perceberem que possuem uma opção de ingresso no ensino superior gratuita no seu município. Aqui quase a totalidade dos alunos (39) concordaram, sendo que apenas 1 se mostrou indiferente e 1 discordou e 3 se abstiveram.

Por fim a Figura 7 mostra quais as tecnologias relacionadas à informática que os alunos informaram ter interesse em aprender. Tecnologias relacionadas à programação, como o desenvolvimento de aplicativos mais complexos e apps de jogos foram as mais citadas, sendo mencionadas 15 vezes. Aprender a trabalhar com ferramentas de design gráfico e do 
VII Congresso Brasileiro de Informática na Educação (CBIE 2018)

Anais do XXIV Workshop de Informática na Escola (WIE 2018)

pacote Office (sendo mencionado exatamente dessa forma) apareceram na sequência, ambos com frequência 5. As respostas em branco nessa questão foram categorizadas como Nenhuma e totalizaram 8 respostas.

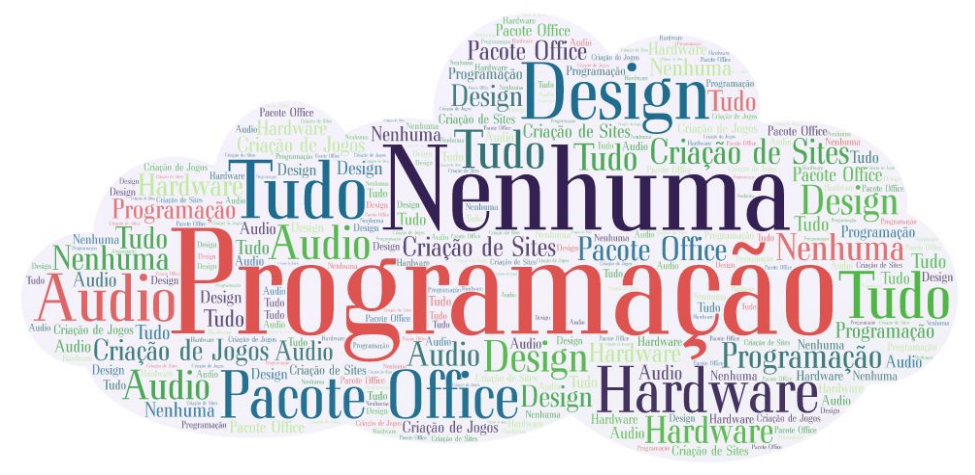

Figura 7 - Tecnologias relacionadas à informática que os alunos gostariam de aprender.

\section{Considerações Finais}

A metodologia adotada neste projeto permitiu que sete das oito escolas públicas de ensino médio do município fossem atendidas, possibilitando assim que um número maior de alunos tivessem acesso a esse tipo de conhecimento e experiência. Cabe ser destacado que a logística de organização de um projeto dessa natureza foi desafiadora, pois envolveu a conciliação da disponibilidade dos recursos materiais, como laboratórios de informática, ônibus para transporte, e dos recursos humanos, como os acadêmicos tutores das oficinas e os alunos das escolas envolvidas e justifica o motivo da oitava escola não ter sido atendida.

A ferramenta App Inventor se mostrou efetiva com sua proposta lúdica de montagem de blocos que abstrai a complexidade das linguagens e ferramentas convencionais, assim como a escolha em explicar como funcionam os conceitos básicos de programação através da construção de uma app do tipo quiz, a qual permitiu a compreensão dos conceitos de uma forma simples, diminuindo os riscos dos alunos sentirem-se desestimulados por não conseguirem executar as tarefas e possibilitou a rápida percepção do resultado do trabalho através de uma app funcional no dispositivo móvel do aluno.

$\mathrm{Na}$ pesquisa a posteriori sobre o cenário de oportunidades ficou evidente que existe um amplo espaço para a condução de projetos que envolvam informática de uma maneira em geral e mais especificamente o ensino de programação, visto que a oficina foi o único projeto nesse tema que os alunos participaram. Entende-se que escola pública, na figura dos seus gestores e professores, não necessita ser protagonista na oferta, mas pode fomentar essa demanda através da colaboração com outras instituições que tenham mais condições de fazê-lo. Por outro lado, esse espaço pode e deve ser mais ocupado por iniciativas vindas dessas instituições e, no caso de IES, projetos de extensão na escola podem ser o meio para viabilizar essa oferta.

Da perspectiva dos alunos concluintes, pôde-se perceber que a participação em um projeto dessa natureza cria a percepção de que a programação é uma ferramenta ao alcance de todos que auxilia na resolução de problemas diversos, fomenta o interesse pela área de Informática/Computação e tem o potencial para aumentar a confiança dos alunos fazendo que 
VII Congresso Brasileiro de Informática na Educação (CBIE 2018)

Anais do XXIV Workshop de Informática na Escola (WIE 2018)

se sintam mais preparados para lidar com os desafios tecnológicos. Como trabalhos futuros pretende-se ofertar na fase II do projeto PampaCode, no segundo semestre de 2018, oficinas avançadas de app Inventor para os alunos concluintes.

\section{Referências}

BORDIN, Andrea et al. (2017) "Ensino de programação para o ensino médio com App Inventor: Um relato de experiência extensionista através da colaboração interinstitucional.” In: Anais do Workshop de Informática na Escola. p. 1179.

Bévort, E., \& Belloni, M. L. (2009) "Mídia-Educação: conceitos, história e perspectivas." Educação e Sociedade, Campinas, v. 30, n. 109, p. 1081-1102, set./dez.

Leôncio, N. N.; de Sousa, R. P.; Melo, R. F. (2017) "Programação em blocos com o Mit App Inventor: Um relato de experiência com alunos do ensino médio.” In: Anais do Workshop de Informática na Escola.. p. 1159.

Câmara, R. H. (2013) “Análise de conteúdo: da teoria à prática em pesquisas sociais aplicadas às organizações.” Gerais: Revista Interinstitucional de Psicologia, v. 6, n. 2, p. 179-191.

Finizola, A. B.; Raposo, E. H. S.; Pereira, M. B. P. N.; Gomes, W. S.; de Araújo, A. L. S. O.; Souza, F. V. C. (2014) "O ensino de programação para dispositivos móveis utilizando o MIT-App Inventor com alunos do ensino médio”. In: Anais do Workshop de Informática na Escola. p. 337.

Júnior, J. C. R. P. et al. (2005) "Ensino de algoritmos e programação: uma experiência no nível médio.” In: XIII Workshop de Educação em Computação (WEI'2005). São Leopoldo, RS, Brasil.

Ribeiro, J.; Manso, M. ; Borges, M. (2016) "Dinâmicas com App Inventor no Apoio ao Aprendizado e no Ensino de Programação". In: Anais do Workshop de Informática na Escola. 2016. p. 271.

Scaico, P. D.; Lopes, D.; Azevedo, M. A.; da Silva, J. C.; Neto, S. V. M.; Falcão, E. S. F. (2012) "Implementação de um Jogo Sério para o Ensino de Programação para Alunos do Ensino Médio Baseado em m-learning." In: Anais do XX Workshop sobre Educação em Computação. Curitiba: PR.

Kologeski, A. L.; Silva, C. G.; Barbosa, D. N. F.; Mattos, R. R.; Miorelli, S. T. (2016) "Desenvolvendo o Raciocínio Lógico e o Pensamento" Computacional: Experiências no Contexto do Projeto Logicando. RENOTE, v. 14, n. 2.

Teixeira, A.; Martins, J. R.; Batistela, F.; Pazinato, A.; Oro, N. (2015) "Programação de computadores para alunos do ensino fundamental: A Escola de Hackers." In: Anais do Workshop de Informática na Escola. p. 112. 